\title{
Optimized design and simulation of a hybrid storage system based on hydrogen as an energy carrier
}

\author{
Maria Alessandra Ancona ${ }^{1 *}$, Michele Bianchi ${ }^{1}$, Lisa Branchini ${ }^{1}$, Francesco Catena ${ }^{1}$, Andrea De Pascale ${ }^{1}$, Federico Ferrari $^{1}$, \\ Francesco Melino ${ }^{1}$ and Antonio Peretto ${ }^{1}$
}

${ }^{1}$ DIN - Università di Bologna, Viale del Risorgimento 2, 40136 Bologna, Italy

\begin{abstract}
The integration of renewable energy sources into the electricity system can contribute to the development of a low-carbon economy. However, due to the intermittency and non-programmability of these sources, problems related to the management of local electricity grids may occur. A possible solution or limitation to these issues is given by the electrical storage. In addition, in the next future, domestic microgrids are expected to play a fundamental role in electric power networks, driving both the academic and industrial research interests in developing highly efficient and reliable conversion and storage technologies. In this study, the behavior of a small-scale hybrid energy system for hydrogen production and storage has been predicted, by means of a developed calculation model, and the operational strategy of the system has been optimized with the aim to maximize the hydrogen production. In addition, with the aim to maximize the overall solar-to-hydrogen chain efficiency, the whole system model has been applied to different operating scenarios, to identify the optimal management strategy to control it.
\end{abstract}

\section{Introduction}

In the last years, the growing attention to the environmental issues, such as the need to reduce pollutant emissions or to find alternatives to the fossil fuels, has led to an increase in the efforts of the scientific research to improve the Renewable Energy Sources (RES) utilization $[1,2]$. These resources, especially wind and solar, in addition to their characteristic of zero emissions production during their operation, present the advantage that they can be employed in those applications where there is no connection to the electricity grid, such as in rural areas [3, 4]. However, the main limit of the renewables is represented by their non-programmability. Consequently, the problem of mismatch between the energy available from the renewables and the energy demand of the users is one of the main issues related to the increase in the RES exploitation. A possible solution to the mismatch problem can be the implementation of Electrical Energy Storage (EES) systems [5-8]. These systems allow to store the energy produced by the renewable sources when it is higher than the one required by the user; then, the stored energy can be used when the renewable source production is not sufficient to satisfy the user's demand. For a photovoltaic system, a common solution is the utilization of a battery bank. The batteries show a fast charge/discharge capacity and a good roundtrip efficiency. On the other hand, batteries are not indicated for long-term storage, mainly for leakage phenomena and low energy density $[9,10]$. Thus, a viable solution can be represented by hybrid battery/hydrogen systems, which combine the good performance of the battery for the short-term storage with the one of the hydrogen for long-term storage. Indeed - being one of the leading options to store energy from renewables and looking promising as low-cost option to store electricity over days, weeks or even months - the hydrogen production may increase the share of renewables [11]. In addition, hydrogen is very versatile. Technologies already available today enable hydrogen to produce, store, move and use energy in different ways: indeed, it can be employed to produce electricity (via fuel cells) or methane, to power homes and feed industry or to fuel cars, trucks, ships and planes.

Concerning the hydrogen storage for a subsequent electricity production, the system is usually made up of an electrolyzer, in order to produce hydrogen through the electrolysis of the water, a hydrogen storage system - e.g. metal hydrides canisters - and a fuel cell. In literature, the optimization of these systems is widely studied [12 - 19].

One of the key aspects to be considered for the hybrid systems is the choice of the Power Management Strategy (PMS). Indeed, in these systems there are many solutions to distribute the energy from the renewable source to the several storage devices and to the electrical load. The choice of the PMS depends on the system configuration and on the aim of the application [20 - 24].

In this context, the aim of this paper is the analysis of an experimental hybrid system set-up, composed of photovoltaic panels, batteries and an electrolyzer, in order to define the optimal operational strategy. In detail, different scenarios have been defined in terms of PV panels and electrolyzer off-design operation, allowing to optimize the PMS of the whole system with the purpose of maximizing the hydrogen production and, consequently, also the overall solar-to-hydrogen chain efficiency. The detail of the novelty of the proposed study is discussed in the following paragraph.

\footnotetext{
${ }^{*}$ Corresponding author: maria.ancona2@unibo.it
} 
The study proposed in this paper analyses a smallscale hybrid photovoltaic/battery/hydrogen system, which consists of PV panels, a battery bank, an electrolyzer and metal hydrides canisters for the hydrogen storage. This paper represents a prosecution of the Authors' previous studies $[25,26]$. While in these previous works $[25,26]$ the models and characterization of each component has been presented, in terms of efficiency evaluation as a function of the boundary and operational conditions, the aim of this paper is to develop a calculation code for the system management, able to simulate the behavior of the whole system and to evaluate the performance of the micro-grid operating with various strategies, to define the optimal one. In particular, the optimization of the management strategy of the system is made to maximize the hydrogen production and thus the system efficiency.

As for the Authors' best knowledge, the main contribution of this work with respect to the literature stands in the proposed method, giving the possibility of evaluating and comparing several management strategies on the same system with the aim to maximize the hydrogen production. The proposed approach is general and can be applied both for the short-term and for the long-term storage. In addition, the relevance of this paper stands in the laboratory size scale analyzed (micro-size) with respect to the large-scale systems usually studied, as a starting point to test the employment of the hybrid storage technology for residential applications. Then, different scenarios - in terms of strategy for the control of the operation of the PV panels, battery bank and hydrogen generator - have been evaluated and compared, with the aim to figure out how the selected strategy influences the system performance. In particular, the performance indicators overall defined for the comparison are the solar-to-hydrogen chain efficiency and the storage efficiency, as well as the hydrogen production. The validation of the management strategies for the hybrid system overall are the object of experimental tests which are in progress now and the related results will be presented in future studies. As a support for this study, an experimental test bench is being set up dedicated to the emulation of the physical devices that are part of the microgrid, with the aim of optimizing the management and control strategies of the entire system.

\section{Microgrid description}

The Figure 1 shows a schematic layout of the micro-grid installed at the laboratory of the University of Bologna. The micro-grid is composed by the following devices:

- two PV panels parallel connected;

- two batteries (lead-acid gel technology);

- a solar charge regulator to connect the PV panels to the batteries; - a DC/DC Converter to feed a DC

load;

- a DC/AC inverter;

- an electrolyzer (PEM technology);

- three metal hydrides canisters for the hydrogen storage.

In Figure 1 the measuring sensors are indicated by the red circles: it can be noticed that voltage (ER) and current (IR) values are measured in every system branch. In addition, the ambient temperature (TR1), the PV panels operating temperature (TR2) and the solar radiation (RR) are measured by means of a pyranometer equipped with thermocouples. Finally, the sensors installed within the hydrogen generator measure the quality of the water $(\mathrm{QR})$ and the volumetric flow rate (LR).The PV panels are made of polycrystalline silicon and are parallel connected. The rated power of a single panel in Standard Test Conditions (STC: Solar radiation $1000 \mathrm{~W} / \mathrm{m} 2$, Cell Temperature $25^{\circ} \mathrm{C}$ with a spectrum of AM 1.5) is equal to $220 \mathrm{~W}$, while the rated efficiency is equal to $15 \%$. The solar charge regulator has the aim to couple the PV panels to the batteries.

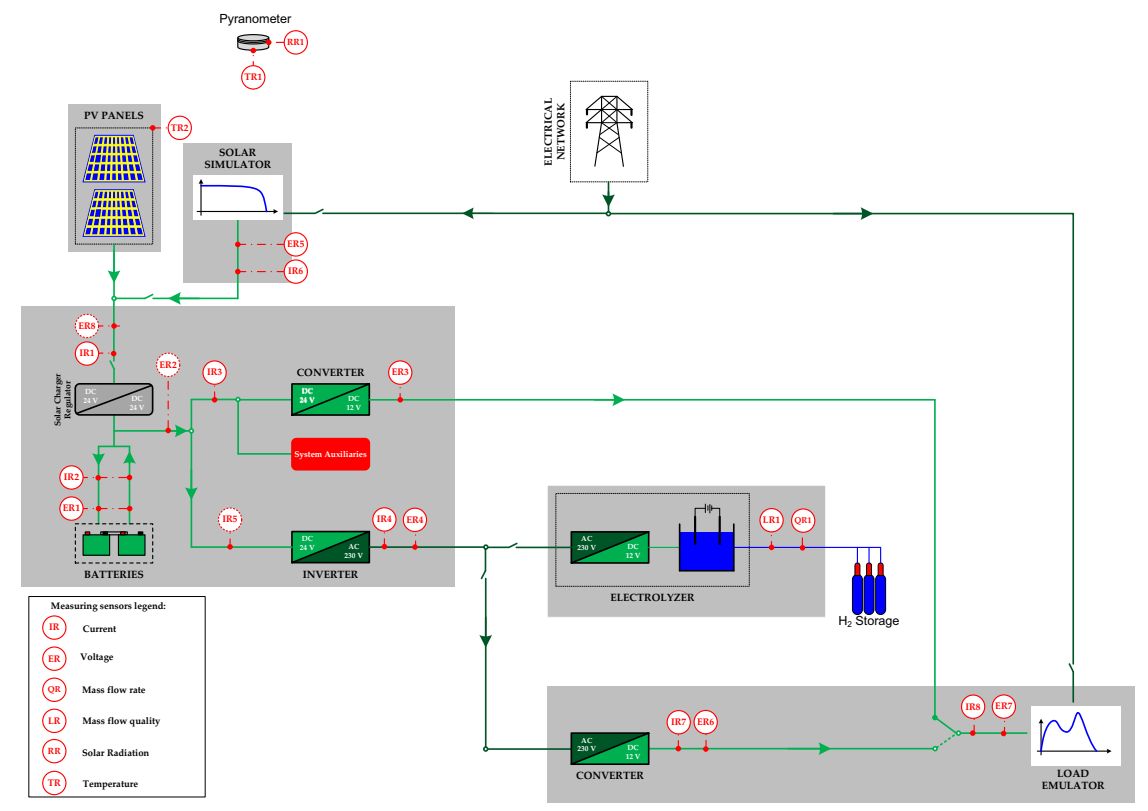

Fig. 1. Layout of the integrated laboratory micro-grid with the installed measuring sensors. 
Its control strategy is the Pulse Width Modulation (PWM) mode. This, in addition to the controller protection functions (including the overcharge and the deep discharge protection) ensures the optimal operating conditions of the batteries. These, each one with a capacity of $55 \mathrm{Ah}$ and a nominal voltage equal to $12 \mathrm{~V}$, are coupled in series; therefore, the resulting voltage is 24 $\mathrm{V}$. The system has a DC/DC converter (Meanwell SD25B-12) to feed a DC load and a DC/AC inverter (Meanwell TS-700-224B) for an AC load. Finally, there is an electrolyzer within an internal $\mathrm{AC} / \mathrm{DC}$ converter to feed the electrolysis process. The produced hydrogen is stored into three metal hydrides canisters at a storage pressure of 10 bar. A more detailed description of the experimental microgrid test bench system can be found in a previous Authors' publication [25], reporting mathematical models of each component and their experimental characterization [26].

\section{Management strategy analysis}

For a system that couples solar arrays, batteries and an electrolyzer, several possible management strategies are available in literature [20-24]. The strategies analyzed in this paper, presented in Figure 2, are focused on the handling of the PV panels and of the electrolyzer. In more detail, the PV panels operating mode is determined by the solar charge regulator: indeed, they can operate in MPP or in PWM mode, related to the possibility of maintaining a different voltage between the PV panels and the batteries. If they are independent from the battery voltage, they can work in MPP mode producing as much power as possible. On the other hand, if their voltage has to be the same as the one of the battery, they work in PWM mode to ensure optimal operating conditions of the batteries. Therefore, their performance depend on the battery State Of Charge (SOC), which is correlated to the voltage. On the other hand, the electrolyzer can work at fixed-point mode or at variable-point: in the first case (Figure 2a) a constant input power feeds the electrolyzer, which works at its maximum efficiency point; in the second case (Figure 2b) the electrolyzer is able to work within a power supply range, then the maximum efficiency is not guaranteed. In all the analyzed strategies, the electrolyzer power supply has the priority.

In particular, in the developed management strategies the power provided by the PV panels is checked for each time step of the considered time horizon:

- if, in the considered time-step, the power produced by the PV panels is lower than the minimum operating power of the electrolyzer, then: if the battery SOC is higher than the minimum admissible SOC value (equal to $30 \%$ for the considered system), the power produced by the PV panels is integrated by the batteries; if the battery SOC is lower than the minimum admissible SOC value, the battery discharge is interrupted in order to avoid a deep discharge of the battery; if, in the considered time-step, the power produced by the PV panels is within the operating range of the electrolyzer, then all the produced electric power is employed by the electrolyzer;

- if, in the considered time-step, the power produced by the PV panels is higher than that required by the electrolyzer, then: if the battery SOC is lower than the maximum admissible SOC value (equal to $100 \%$ for the considered system), the difference between the power produced by the PV panels and the maximum operating power of the electrolyzer is employed to charge the batteries; if the battery SOC reaches the maximum admissible SOC value, the battery charge is interrupted and the excess power is wasted.

The power required by the electrolyzer depends on its operating mode. If it works at fixed-point mode the reference parameter for the energy flow management is the supply power corresponding to the maximum hydrogen generator efficiency. On the contrary, if the electrolyzer works at variable-point mode, the reference parameters for the energy flow management are the minimum and the maximum allowed supply powers of the hydrogen generator. In this case, when the power produced by the PV panels is outside of the operating range of the electrolyzer, then the latter is supplied at the maximum power.

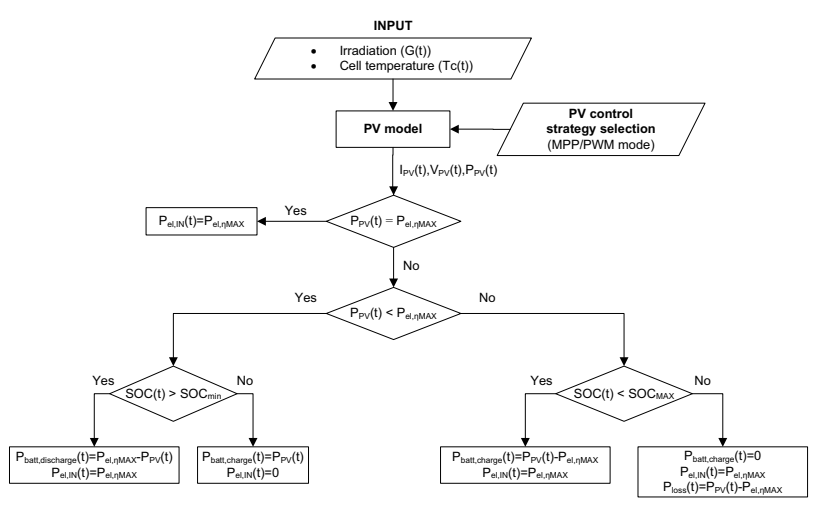

a) $M P P / P W M$ strategy with hydrogen generator at fixed-point $(H G F)$.

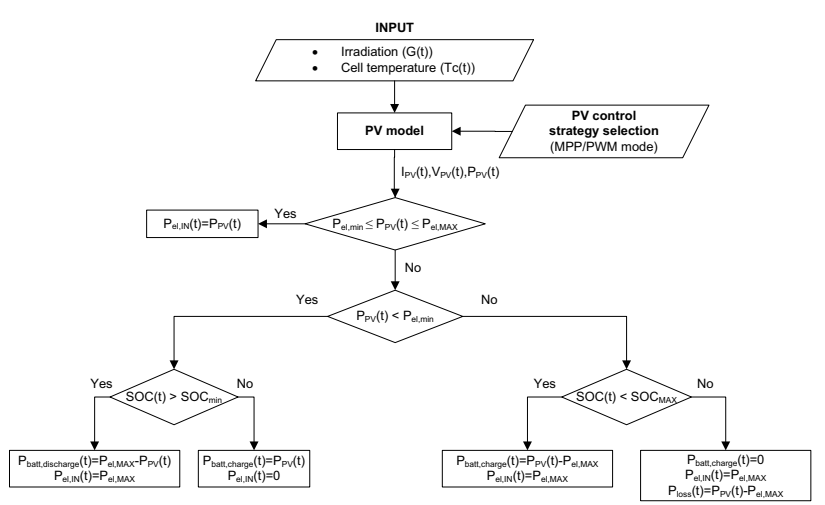

b) $M P P / P W M$ strategy with hydrogen generator at variable-point $(H G V)$.

Fig. 2. Flow chart of the analyzed management strategies.

\footnotetext{
${ }^{*}$ Corresponding author: maria.ancona2@unibo.it
} 
In this study four different strategies have been analyzed. In addition, for each strategy, the electrolyzer has been evaluated in two operating modes: fixed-voltage mode and variable-voltage mode. Then, a total of eight cases have been considered. The Table 1 summarizes the features of the eight case studies.

A system simulation model has been developed to manage the power fluxes through the different components. Since the model has to simulate the behavior of the PV panels, it requires the values of the irradiation $(R R)$ and of the cell temperature $\left(\mathrm{T}_{\text {cell }}\right)$ as external inputs Indeed, starting from these values it is possible to estimate the power produced by the PV panels and feeding the system. The values of the irradiation and of the cell temperature used in this analysis have been recorded during laboratory tests; the same values have been used to compare the different case studies. Figure 3 shows the trend of the irradiation recorded during the tests as a function of the time (time step equal to 5 seconds). In order to compare the management strategies above described, first of all the overall solar-to-hydrogen efficiency $\left(\eta_{\text {tot }}[-]\right)$ has been used [25]:

$$
\eta_{t o t}=\frac{m_{H_{2}} \cdot H H V_{H_{2}}}{\int_{0}^{t} R R \cdot S_{P V} d t}
$$

where $m_{H_{2}}[\mathrm{~kg}]$ is the hydrogen produced during the considered time horizon $(t), H H V_{H_{2}}[\mathrm{~kJ} / \mathrm{kg}]$ is the higher heating value of the hydrogen, $R R\left[\mathrm{~W} / \mathrm{m}^{2}\right]$ is the time varying solar radiation and $S_{P V}\left[\mathrm{~m}^{2}\right]$ is the total surface of the PV panels. The results in terms of $\eta_{t o t}$ are shown in Figure 4 for each simulated scenario. In addition, in order to better explain these results, the hydrogen production, as a function of the power at the inlet of the electrolyzer, is presented in Figure 5, while the trend of the state of charge of the batteries, as a function of the time step, is presented in Figure 6.

Table 1. Features of the eight analyzed management strategies.

\begin{tabular}{|c|c|c|c|}
\hline Case & PV panels & \multicolumn{2}{|c|}{ Hydrogen generator } \\
\hline $\begin{array}{c}\text { MPP-HGF fixed- } \\
\text { voltage }\end{array}$ & MPP & Fixed-point & Fixed-voltage \\
\hline $\begin{array}{c}\text { MPP-HGF } \\
\text { variable-voltage }\end{array}$ & MPP & Fixed-point & $\begin{array}{c}\text { Variable- } \\
\text { voltage }\end{array}$ \\
\hline $\begin{array}{c}\text { MPP-HGV fixed- } \\
\text { voltage }\end{array}$ & MPP & Variable-point & Fixed-voltage \\
\hline $\begin{array}{c}\text { MPP-HGV } \\
\text { variable-voltage }\end{array}$ & MPP & Variable-point & $\begin{array}{c}\text { Variable- } \\
\text { voltage }\end{array}$ \\
\hline $\begin{array}{c}\text { PWM-HGF fixed- } \\
\text { voltage }\end{array}$ & PWM & Fixed-point & Fixed-voltage \\
\hline $\begin{array}{c}\text { PWM-HGF } \\
\text { variable-voltage }\end{array}$ & PWM & Fixed-point & $\begin{array}{c}\text { Variable- } \\
\text { voltage }\end{array}$ \\
\hline $\begin{array}{c}\text { PWM-HGV fixed- } \\
\text { voltage }\end{array}$ & PWM & Variable-point & Fixed-voltage \\
\hline $\begin{array}{c}\text { PWM-HGV } \\
\text { variable-voltage }\end{array}$ & PWM & Variable-point & $\begin{array}{c}\text { Variable- } \\
\text { voltage }\end{array}$ \\
\hline
\end{tabular}

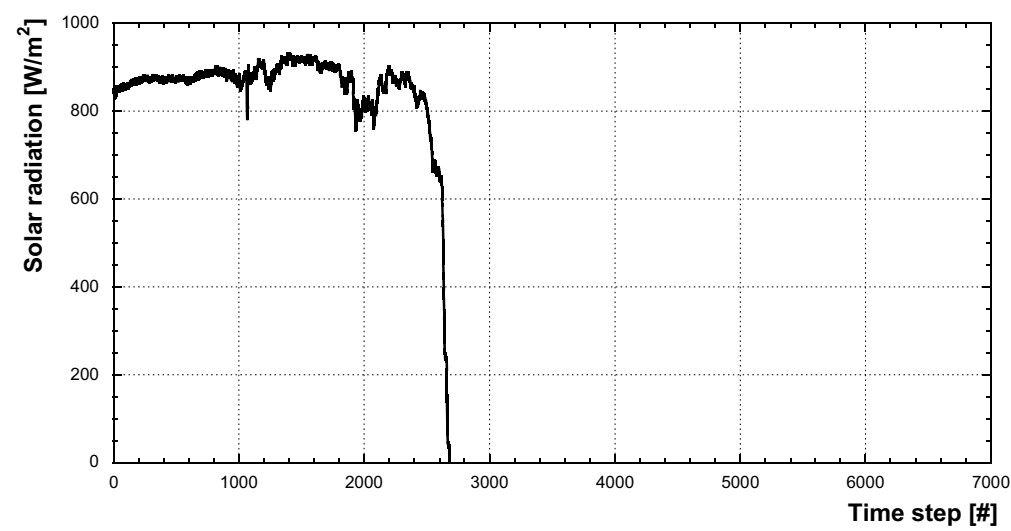

Fig. 3. Experimental trend of the irradiation in the considered time horizon (each time step corresponds to $5 \mathrm{~s}$ ).

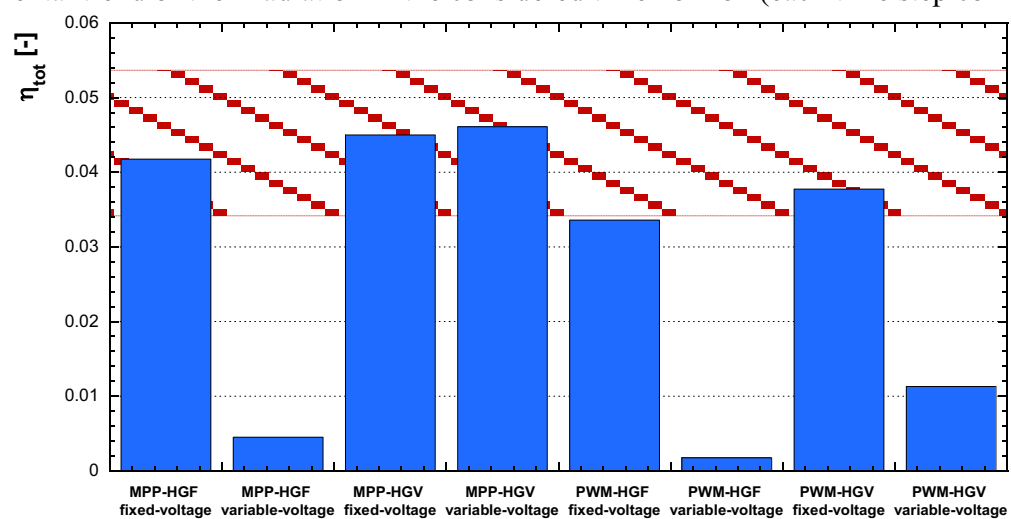

Fig. 4. Overall solar-to-hydrogen efficiency obtained for the analyzed scenarios. The red area represents the efficiency range experimentally evaluated in [25].

\footnotetext{
* Corresponding author: maria.ancona2@unibo.it
} 
As it can be observed in Figure 4, the best scenario is the MPP-HGV at variable-voltage, with the PV panels working at the maximum power and the hydrogen generator at variable-point and at variable-voltage, with a value of $\eta_{\text {tot }}$ of about 0.046 .

Indeed, in this case, the PV power production is at the maximum (MPP) and - depending on the considered time step and except for a few instants - the panels and/or the batteries can provide a higher value of power with respect to the upper limit of the electrolyzer operating range. To this respect, in the first part of the analyzed period the PV panels production is high and quite stable (see Figure 3) allowing to feed the electrolyzer and to charge the batteries (see Figure 6). Indeed, in this stage the batteries show the maximum SOC during the tests, with a value of about 0.6 for the scenario MPP-HGV at variable-voltage. On the other hand, in the second part of the analyzed period, no production from PV is registered and the batteries can provide power to the electrolyzer, depending on the considered strategy; this behavior can be seen in Figure 6, in which the SOC of the batteries starts to decrease in correspondence of the PV panels inactivity. Consequently, in the MPP-HGV at variable-voltage case, the electrolyzer can be operated at its maximum power for the larger part of the analyzed period, allowing at the same time to reach the maximum hydrogen production (see Figure 5).

The small difference between this case and the scenario MPP-HGV at fixed-voltage is given by the different couple voltage-current at the inlet of the electrolyzer and by the conversion efficiency of the converter. On the contrary, in the other scenarios the variable-voltage mode is disadvantageous, especially when the hydrogen generator works at fixed-point (HGF). This evidence can be explained considering that the electrolyzer always works at the point of maximum efficiency, also when the power available from the PV panels and the batteries is higher with respect to the operating point of the electrolyzer.

This assumption - being the PV production, in the first part of the analyzed time period, always higher than the electrolyzer required input power - causes a faster charge of the batteries for HGF variable voltage strategies with respect to the corresponding fixed-voltage ones (see Figure 6a), since the power corresponding to the maximum efficiency point is lower for the variable voltage operation than for the fixed voltage operation. For the same reason, the discharge process of the HGF variable voltage scenarios results slower. Furthermore, in the case of fixed-voltage, the operating point of the variable-voltage scenario $(120 \mathrm{~W})$ causes the minimum production of hydrogen (Figure 5).

The explanation of the cases PWM-HGV is similar to the one of the cases MPP-HGV, even if the results are quite different. Indeed, in these cases the number of intervals in which the PV panels directly supply the electrolyzer is larger (the PV panels work in PWM mode and then produce a lower quantity of power) and then there are more time steps in which the electrolyzer is not supplied by the maximum power.

Finally, relating to the HGV scenarios, from Figure 6 it can be observed the same batteries behavior for fixed PV operating mode, independently from the electrolyzer voltage management. Indeed, when the PV panels produce a value of power higher or lower compared to the operating range of the electrolyzer, then, in this scenarios (HGV), the latter is supplied by the maximum operating power (it's the same value for fixed-voltage and variablevoltage); the only difference stands in the PV operating mode.

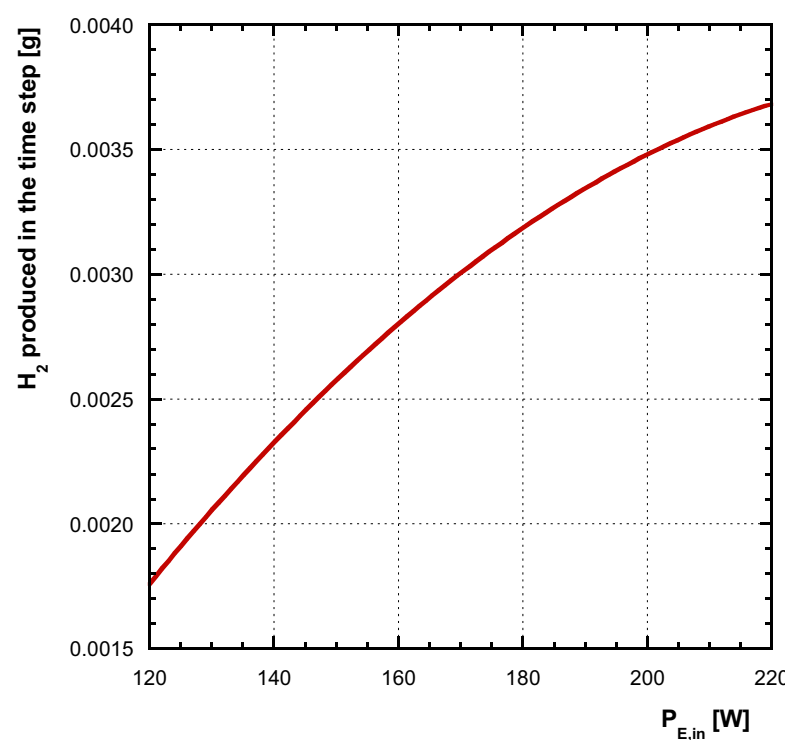

Fig. 5. Hydrogen production as a function of the power at the inlet of the electrolyzer.

In addition, in Figure 4 it is also shown the overall solar-to-hydrogen efficiency range evaluated experimentally in [25] (red area in the figure). This range goes from $3.4 \%$ to $5.3 \%$, on the basis of the operating conditions. To this respect, some of the strategies analyzed in this paper present a value of the efficiency included in this range, but the considered strategies are quite different from the experimental process.

Indeed, the PV panels in the experimental set-up works in PWM mode but the charging and discharging processes are different from the studied strategies: the charging process consists in directing the solar radiation energy, converted by the PV panels, to the batteries by means of the solar charge regulator and once the batteries are completely charged, the PV panels are disconnected and the stored energy is discharged to the hydrogen generator.

\footnotetext{
* Corresponding author: maria.ancona2@unibo.it
} 

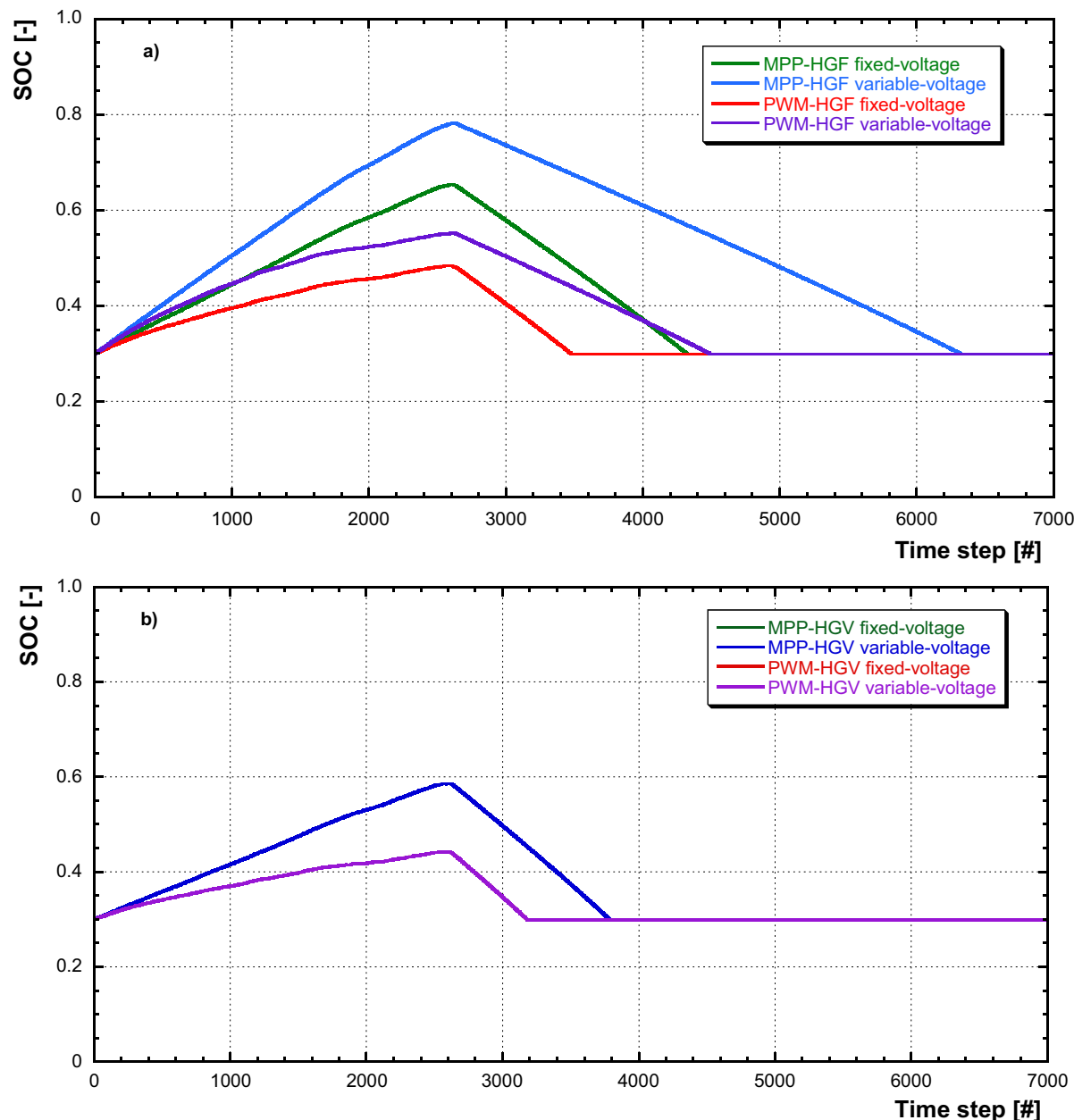

Fig. 6. Trend of the batteries SOC as a function of the time step for: a) HGF strategies and b) HGV strategies.

Furthermore, a second performance parameter has been considered, in order to evaluate the system as a storage itself. In particular, the storage efficiency ( $\eta_{\text {sto }}[-$ ]) takes into account the energy provided in input to the system by the PV panels (instead of the solar radiation), as an integral of the power produced $\left(P_{P V}[\mathrm{~kW}]\right)$ during the considered time horizon:

$$
\eta_{\text {sto }}=\frac{m_{\mathrm{H}_{2}} \cdot H H V_{\mathrm{H}_{2}}}{\int_{0}^{t} P_{P V} d t}
$$

In Figure 7 the values of the storage efficiency for the analyzed scenarios are shown. The trend of this parameter as a function of the considered strategy is similar to the one of the solar-to-hydrogen overall chain efficiency, but the values are evidently higher since the PV panels efficiency is not taken into account. Due to this, the strategies based on the PWM mode are more competitive with respect to the strategies based on the MPP mode. Indeed, the MPP mode shows better PV panel efficiency with respect to the PWM mode and in the storage efficiency this penalizing factor is not accounted. Then, in this case the better strategy is the PWM-HGV with fixedvoltage, showing a value of efficiency equal to about 35 $\%$.

\section{CONCLUSIONS}

In the last years, the increase in the penetration of renewable energy sources into the electrical system has been promoted, due to the need of reducing pollutant emissions and finding alternatives to the fossil fuels employment. However, as a consequence of the intermittency and non-programmability of these sources, issues related to the management of local and regional electric networks has been registered, such as the mismatch between the energy available from the renewables and the energy demand of the users. In order to limit (or avoid) these problems, the electrical energy storage is recognized as a fundamental solution.

In this paper, an experimental micro-grid composed of photovoltaic panels, batteries and an electrolyzer has been modelled and analyzed.

In addition, the model has been applied to different scenarios - in terms of the whole system operation management - with the aim to maximize the hydrogen production (i.e. the overall solar-to-hydrogen chain efficiency) and, consequently, to identify the optimal management strategy to control the system. 


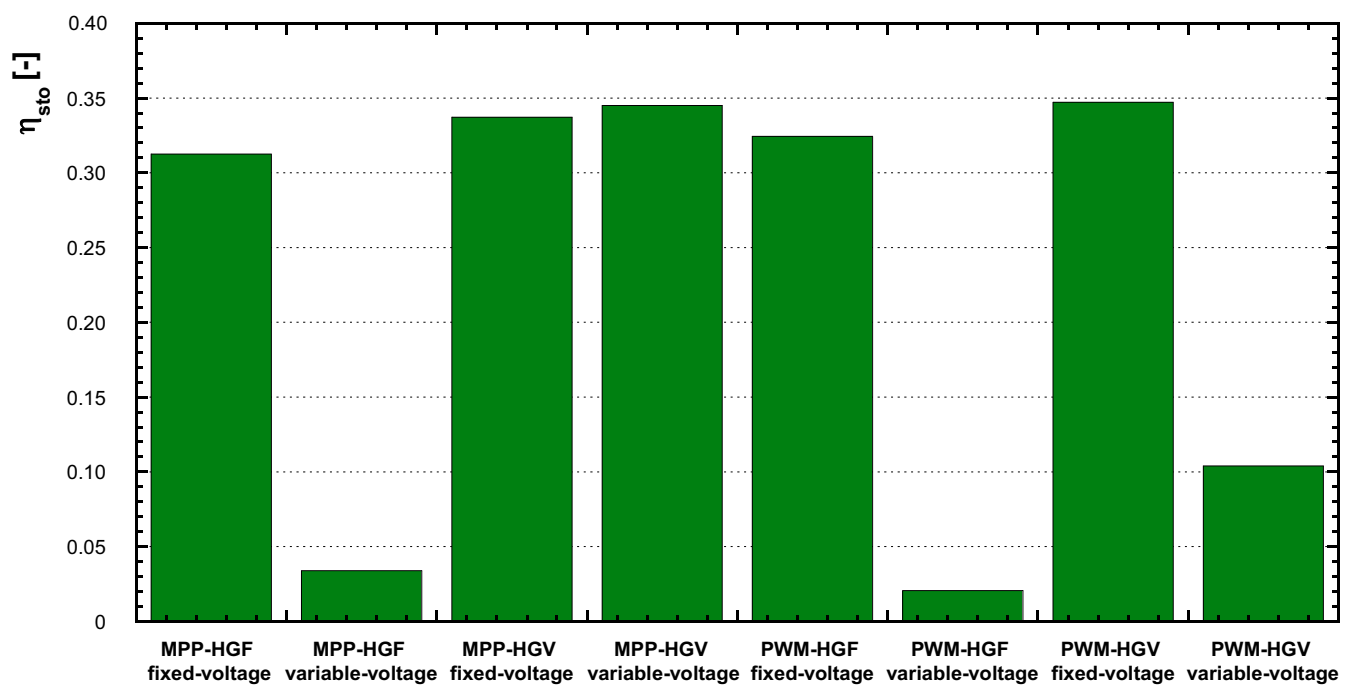

Fig. 7. Storage efficiency obtained for the analyzed scenarios.

To this respect, eight scenarios have been simulated and analyzed, considering the photovoltaic panels operating in maximum power point (MPP) or pulse width modulation (PWM) mode, the hydrogen generator operating at fixed (HGF) or variable point (HGV) and at fixed or variable voltage. In order to compare the analyzed cases, two performance indexes have been considered: the overall solar-to-hydrogen chain efficiency and the storage efficiency (which exclude the photovoltaic conversion efficiency by considering the photovoltaic panels production as energy input of the system).

The best scenario resulting from the carried out analysis is the MPP-HGV at variable-voltage, with the photovoltaic panels working at the maximum power and the hydrogen generator at variable-point and at variablevoltage, with a value of the overall solar-to-hydrogen chain efficiency equal to about $4.6 \%$. Indeed, in this case, the PV panels work at the maximum power production and - except for a few instants - along with the batteries always provide a higher value of power with respect to the upper limit of the electrolyzer operating range. Consequently, the electrolyzer can be operated at its maximum power for the larger part of the analyzed period, allowing at the same time to reach the maximum hydrogen production. This scenario is one of the best also from the storage efficiency viewpoint, even if the maximum value of this performance parameter is obtained for the PWM-HGV with fixed-voltage scenario (slightly lower than $35 \%$ ), since the lower PV efficiency characterizing the PWM mode with respect to the MPP mode is not accounted in the storage efficiency evaluation.

Finally, it must be pointed out that the obtained results - in terms of identified optimal management strategy - are obviously affected by the sizes of the systems composing the laboratory set-up and, in particular, by the correlation of the sizes between the considered energy systems. For this reason, to give a complete optimization of the management strategy, future works will aim at the integration, within the microgrid, of some electronic devices for the emulation of energy systems inspired by the logic of hardware in the loop, in order to better test the management algorithms developed.

\section{NOMENCLATURE}

\begin{tabular}{ll}
\multicolumn{2}{l}{ Acronyms } \\
AC & Alternate Current \\
DC & Direct Current \\
EES & Electrical Energy Storage \\
FC & Fuel Cell \\
HGF & Hydrogen Generator Fixed-point \\
HGV & Hydrogen Generator Variable-point \\
MPPT & Maximum Power Point Tracking \\
PEM & Proton Exchange Membrane \\
PMS & Power Management Strategy \\
PV & Photovoltaic \\
PWM & Pulse Width Modulation \\
RES & Renewable Energy Sources \\
SOC & State Of Charge \\
STC & Standard Test Conditions
\end{tabular}

\section{References}

1. Wang, J., Zhong, H., Ma, Z., Xia, Q., Kang, C. Review and prospect of integrated demand response in the multi-energy system. Applied Energy, 202 (2017) 772-782.

2. Zia, M. F., Elbouchikhi, E., Benbouzid, M. Microgrids energy management systems: A critical review on methods, solutions, and prospects. Applied Energy, 222 (2018) 1033-1055.

3. Bhandari, B., Lee, K. T., Lee, C. S., Song, C. K., Maskey, R. K., Ahn, S. H. A novel off-grid hybrid power system comprised of solar photovoltaic, wind, and hydro energy sources. Applied Energy, 133 (2014) 236-242.

4. Yan, J., Zhai, Y., Wijayatunga, P., Mohamed, A. M., Campana, P. E. Renewable energy integration with mini/micro-grids. Applied Energy, 201 (2017) 241244.

\footnotetext{
${ }^{*}$ Corresponding author: maria.ancona2@unibo.it
} 
5. Aneke, M., Wang, M. Energy storage technologies and real life applications-A state of the art review. Applied Energy, 179 (2016) 350-377.

6. Bianchi, M., Branchini, L., Ferrari, C., Melino, F. Optimal sizing of grid-independent hybrid photovoltaic-battery power systems for household sector. Applied Energy, 136 (2014) 805-816.

7. Bianchi, M., Branchini, L., De Pascale, A., Melino, F. Storage solutions for renewable production in household sector. Energy Procedia, 61 (2014) 242245.

8. Akinyele, D. O., Rayudu, R. K. Review of energy storage technologies for sustainable power networks. Sustainable Energy Technologies and Assessments, 8 (2014) 74-91.

9. Zhou, K., Ferreira, J. A., De Haan, S. W. H. Optimal energy management strategy and system sizing method for stand-alone photovoltaic-hydrogen systems. International Journal of Hydrogen Energy, 33(2) (2008) 477-489.

10. Spiers D. Chapter II-2-B - Batteries in PV Systems. In: McEvoy's Handbook of Photovoltaics (Third Edition); 2018, p.789-43. https://doi.org/10.1016/B978-0-12-809921$6.00021-5$

11. Report IEA - The Future of Hydrogen (2019), https://www.iea.org/hydrogen2019/

12. Han, Y., Chen, W., Li, Q., Yang, H., Zare, F., Zheng, Y. Two-level energy management strategy for PVFuel cell-battery-based DC microgrid. International Journal of Hydrogen Energy, 44 (2019) 1939519404.

13. Parra, D., Walker, G. S., Gillott, M. Modeling of PV generation, battery and hydrogen storage to investigate the benefits of energy storage for single dwelling. Sustainable Cities and Society, 10 (2014) $1-10$.

14. Zhou, M., Liu, Y. Theoretical study on direct coupling of a PV array to a PEM electrolyser. In: 2013 International Conference on Materials for Renewable Energy and Environment. IEEE, 1 (2013) 52-56

15. McDonagh, S., Ahmed, S., Desmond, C., Murphy, J. D. Hydrogen from offshore wind: Investor perspective on the profitability of a hybrid system including for curtailment. Applied Energy, 265 (2020) 114732

16. Li, C. H., Zhu, X. J., Cao, G. Y., Sui, S., Hu, M. R. Dynamic modeling and sizing optimization of standalone photovoltaic power systems using hybrid energy storage technology. Renewable Energy, 34(3) (2009) 815-826.

17. Han, G., Kwon, Y., Kim, J. B., Lee, S., Bae, J., Cho, E., Lee, B. J., Cho, S., Park, J. Development of a high-energy-density portable/mobile hydrogen energy storage system incorporating an electrolyzer, a metal hydride and a fuel cell. Applied Energy, 259 (2020) 114175.

18. Firtina-Ertis, I., Acar, C., Erturk, E. Optimal sizing design of an isolated stand-alone hybrid wind- hydrogen system for a zero-energy house. Applied Energy, 274 (2020) 115244.

19. Esfahani, I. J., Ifaei, P., Kim, J., Yoo, C. Design of hybrid renewable energy systems with battery/hydrogen storage considering practical power losses: a MEPoPA (modified extended-power pinch analysis). Energy, 100 (2016) 40-50.

20. Behzadi, M. S., Niasati, M. Comparative performance analysis of a hybrid $\mathrm{PV} / \mathrm{FC} /$ battery stand-alone system using different power management strategies and sizing approaches. International Journal of Hydrogen Energy, 40(1) (2015) 538-548.

21. Cano, M. H., Kelouwani, S., Agbossou, K., Dubé, Y. Power management system for off-grid hydrogen production based on uncertainty. International Journal of Hydrogen Energy, 40(23) (2015) 72607272.

22. Ipsakis, D., Voutetakis, S., Seferlis, P., Stergiopoulos, F., Elmasides, C. Power management strategies for a stand-alone power system using renewable energy sources and hydrogen storage. International Journal of Hydrogen Energy, 34(16) (2009) 7081-7095.

23. dos Santos Neto, P. J., Barros, T. A., Silveira, J. P., Filho, E. R., Vasquez, J. C., Guerrero, J. M. Power management techniques for grid-connected DC microgrids: A comparative evaluation. Applied Energy, 269 (2020) 115057.

24. de la Hoz, J., Martín, h., Alonso, A., Luna, A. C., Matas, J., Vasquez, J. C., Guerrero, J. M.Regulatoryframework-embedded energy management system for microgrids: The case study of the Spanish selfconsumption scheme. Applied Energy, 251 (2019) 113374

25. Ancona, M. A., Bianchi, M., Branchini, L., De Pascale, A., Melino, F., Peretto, A., Rosati, J., Scarponi, L. B. From solar to hydrogen: Preliminary experimental investigation on a small scale facility. International Journal of Hydrogen Energy, 42(33) (2017) 20979-20993.

26. M. A. Ancona, M. Bianchi, L. Branchini, F. Catena, A. De Pascale, F. Melino, A. Peretto. Modelling and validation of a small-scale hybrid photovoltaicbattery-electrolyzer system. Proceedings of the $8^{\text {th }}$ European Fuel Cell Piero Lunghi Conference EFC2019, 9-11 December, 2019, Naples, Italy. 